\title{
Structural Invariance of Declarative Knowledge Across the Adult Lifespan
}

\author{
Luc Watrin $^{1}$, Ulrich Schroeders ${ }^{2}$, Oliver Wilhelm ${ }^{1}$ \\ ${ }^{1}$ Institute of Psychology and Education, Ulm University, Germany \\ ${ }^{2}$ Institute of Psychology, University of Kassel, Germany
}

\begin{abstract}
Author Note
Luc Watrin iD https://orcid.org/0000-0003-4343-3781

Ulrich Schroeders iD https://orcid.org/0000-0002-5225-1122

Oliver Wilhelm (iD https://orcid.org/0000-0001-7980-1166
\end{abstract}

We have no conflicts of interest to disclose. We confirm that the work conforms to Standard 8 of the American Psychological Association's Ethical Principles of Psychologists and Code of Conduct. We thank Diana Steger for developing the large item pool that we partially used in this study and Alexander Robitzsch for the implementation of the joint estimation procedure in the sirt package.

This research was supported by a grant from the Deutsche Forschungsgemeinschaft (DFG) to Ulrich Schroeders and Andrea Hildebrandt (SCHR 1591/1-1 and HI 1780/4-1) as part of the Priority Program 1646 "Education as a Lifelong Process". Data from this study has partly been used in Schroeders et al. (2021). Both the research question and the methodology differ substantially. The data and materials supporting the findings of this study are available at https://osf.io/46gh7/. 
Correspondence concerning this article should be addressed to Luc Watrin, Institute of Psychology and Education, Ulm University, Albert-Einstein-Allee 47, 89081 Ulm, Germany, Email: luc.watrin@uni-ulm.de

(C)American Psychological Association, 2021. This paper is not the copy of record and may not exactly replicate the authoritative document published in the APA journal. The final article is available, upon publication, at Psychology and Aging. 


\begin{abstract}
The differentiation-dedifferentiation hypothesis of general cognitive ability has been widely studied, but comparable research on crystallized intelligence is scarce. To close this gap, we conducted an empirical test of the age differentiation hypothesis of declarative knowledge as proposed in Cattell's investment theory, which predicts that knowledge differentiates into diverse forms after compulsory education ends. Thereto, a cross-sectional sample of 1,629 participants aged 18 to 70 years $(M=45.3)$ completed a comprehensive knowledge test comprising 120 broadly sampled questions from 12 knowledge domains, as well as a measure of openness/intellect. To investigate age-related differences in the level and structure of knowledge, we performed invariance tests in local structural equation models. The results did not provide any evidence for age-related differentiation of declarative knowledge but indicated age-related differences in the mean structure. Higher levels in openness/intellect were associated with higher levels in knowledge but not with more differentiated structure of knowledge. Contrary to predictions of the investment theory, our results suggest that declarative knowledge is age invariant across major parts of the adult lifespan.
\end{abstract}

\title{
Public Significance Statement
}

Results of this study suggest that the structure of general fact knowledge does not change across the adult lifespan. Knowledge is strongly related to intellectual openness and this association becomes stronger with increasing age. Fact knowledge is a crucial component of human intelligence that deserves more attention as either predictor, covariate, or outcome of different life courses.

Keywords: crystallized intelligence, declarative knowledge, openness, age differentiation, measurement invariance 


\section{Structural Invariance of Declarative Knowledge Across the Adult Lifespan}

Throughout our life, we acquire vast amounts of knowledge in various domains. In childhood and adolescence, knowledge acquisition follows a developmental cascade and expands through rather homogenous formal education settings. Once compulsory education is completed, the knowledge we seek and learn becomes increasingly diverse and idiosyncratic. In early adulthood, we pursue professional education that matches our interests or which we deem instrumental. It seems logical that the way we organize our learning shapes the level and structure of vocational and avocational knowledge we accumulate over time. Although agerelated differences in the level and structure of general cognitive ability have been investigated extensively, comparable research for crystallized intelligence is scarce. In this article, we examine age-related differences in the level and structure of declarative knowledge as a key component of crystallized intelligence and discuss their theoretical underpinning. We also elaborate on methodological aspects that have to be considered when studying age-related differences in latent abilities. Finally, we extend the analyses of age differentiation of crystallized intelligence by investigating the structure of declarative knowledge across manifestations of the personality factor openness/intellect.

\section{Cattel's Age Differentiation Hypothesis of Crystallized Intelligence}

Cattell's $(1971,1987)$ investment theory still is an influential idea about the development of cognitive abilities that has sparked a large body of research (e.g., Ackerman, 1996; Baltes et al., 1999; Ferrer \& McArdle, 2004; Li et al., 2004). Two prominent predictions of this theory are that a) from a young age on, fluid intelligence (gf) is invested to build skills, knowledge, and language-related abilities and that $b$ ) the link between fluid and crystallized abilities becomes less important with age. Cattell stated the latter because he acknowledged that factors beyond gf, 
such as the school curriculum, social, familial, and other influences, would increasingly shape which crystallized abilities an individual acquires over time. Despite its popularity, the evidence for the theoretical assumptions - that gf is the temporal upstream and causally responsible factor for gc (e.g., Ferrer et al., 2007; Ferrer \& McArdle, 2004) and that the association of fluid and crystallized intelligence changes with age (e.g., Hartung et al., 2018) - is rather weak.

However, another major assumption from the theory has received less attention: Cattell (1987) also predicted that crystallized intelligence differentiates into a wide diversity once the harmonizing influence of compulsory education no longer applies. He stated that the "pattern common to all people who attend school should begin to disperse" (p. 142) when school ends, and that crystallized intelligence "extends[s] into Protean forms" (p.143) when people start to acquire knowledge related to individually chosen vocational and avocational paths. In other words, he argued that compulsory education creates a somewhat standardized environment within which preferences and choices of students hardly matter. If children spend a substantial amount of time in school and are taught a common set of subjects, knowledge in these subjects should tend to correlate more highly. Once school and its equalizing forces end, the level and structure of crystallized intelligence should diversify: Individuals then choose educational and occupational learning environments based on their interests, abilities, financial opportunities, etc. Differences in life and learning pathways should lead to differences in the acquired knowledge structures. Acquiring knowledge in certain subjects should come at the cost of acquiring less or no knowledge in other subjects. For example, most of us may acquire very limited knowledge of the legal system, while others may learn some basics due to personal circumstances, and still others may earn their living by studying and practicing law. Importantly, since this more idiosyncratic knowledge acquisition does not adhere to a common curriculum, knowledge in 
different areas becomes increasingly independent of each other. More specifically, he stated that "the correlations constituting the earlier crystallized ability pattern should begin to be less dependable" (p. 142). In statistical terms, we interpret Cattell's hypothesis as an age-related differentiation hypothesis akin to the differentiation hypothesis of general cognitive ability (e.g., Garrett, 1946), predicting changes not only in the mean but also in the covariance structure of gc. That is, differentiation is expressed in decreasing correlations between knowledge domains.

Different conceptualizations of gc exist. Cattell (1987) emphasized the importance of knowledge in diverse content domains, whereas Carroll (1993) defined gc with language-related abilities (e.g., reading and listening comprehension). Although vocabulary tasks are often used to measure gc, they can be criticized as overly narrow operationalization of gc, that is, knowledge about word meaning in a variety of domains (Schipolowski et al., 2014). In the current article, we therefore adhere to Cattell's conceptualization of gc as a broad factor of declarative knowledge. In the following sections, we will first elaborate on potential mechanisms which might cause increasingly diverse and separable knowledge structures over age. We then address methodological aspects to consider in the investigation of differentiation of latent constructs. Finally, we review the available evidence regarding age differentiation of declarative knowledge. The Cumulative Effect of Prior Knowledge

Crystallized intelligence is usually deemed one of the most important broad ability factors in consensual models of human cognitive ability (e.g., Schneider \& McGrew, 2012). One aspect that sets it apart from most other abilities (e.g., fluid intelligence, mental speed, memory) is that its growth is cumulative in nature. Prior knowledge can facilitate or even be necessary for the acquisition of further knowledge (e.g., Ackerman \& Beier, 2006; Beier \& Ackerman, 2005; Hambrick et al., 2008). This has been termed the "Matthew effect" or the "rich-get-richer effect" 
of knowledge acquisition but has also been investigated as the "knowledge-is-power hypothesis" (e.g., Hambrick \& Engle, 2002; Witherby \& Carpenter, 2021). For example, prior knowledge in basic calculus facilitates or might be a prerequisite for the acquisition of advanced mathematics, which might facilitate acquiring additional and more advanced math knowledge (Geary et al., 2017). So clearly, differences in the initial level of knowledge can foster subsequent knowledge gains, which refers to the mean level structure. The idea that the Matthew effect strengthens the cumulative effect of knowledge acquisition over time has been taken up in simulations that conceptualize intelligence as evolving networks (Savi et al., 2019). In these simulations of the development of knowledge networks, the cumulative character of knowledge acquisition results in a bifurcation of knowledge levels over time. However, changes in mean differences (i.e., increase in variance) do not necessarily imply changes in the correlations between knowledge domains. From a longitudinal perspective, it depends on the correlation of the initial level and change. If both are perfectly correlated, differentiation cannot occur because later knowledge is exclusively a function of prior knowledge. The more the level-change correlation deviates from unity, the more room there is for other determinants of knowledge acquisition besides prior knowledge. For example, time, motivation or opportunities are all factors impacting learning beyond prior knowledge and fluid intelligence. Such multiple determination of knowledge gains set the ground for differential development of knowledge structures over and above differential knowledge trajectories.

While convincing on a theoretical level, the empirical evidence for the Matthew effect is mixed (e.g., Simonsmeier et al., 2021), even for applications with a strong cumulative character such as reading acquisition (e.g., Pfost et al., 2014). Studies conducted with high-school students often seem to favor the compensation rather than the Matthew effect (e.g., Schroeders, 
Schipolowski, et al., 2016; Skibbe et al., 2008). An explanation is that in the formalized learning environment of school education, initial knowledge differences are often leveled out because educational systems presumably prioritize a minimum level of education for all pupils rather than fostering more gifted children (e.g., Schroeders, Schipolowski, et al., 2016). However, comparing learning during schooling vs. vacation periods (Alexander et al., 2001; Cooper et al., 1996), we might conclude that the Matthew effect exists for an individual learner who has the opportunity and the willingness to learn at self-chosen pace and intensity. This would be in line with Cattell's (1987) notion about the declarative knowledge that extends into Protean forms after compulsory school education when the above-mentioned multiple determination becomes more apparent. Because learning environments diversify and self-initiated learning processes become pivotal for the continual acquisition of knowledge, knowledge structures might differentiate. However, no convincing evidence for such claims has been provided so far.

\section{The Effect of Openness/Intellect}

Intellectual investment traits describe a set of personality traits that have been hypothesized to causally influence if and how people invest time and fluid intelligence in acquiring knowledge (e.g., Ackerman, 1996; Cattell, 1987; Ziegler et al., 2018). The idea that preferences for cognitively demanding activities affect cognition has been picked up in Ackerman's (1996) theory of adult intellectual development, in which cognitive, affective, and conative factors are intertwined to form so-called trait complexes (Ackerman, 2003). Intellectual investment traits play an important cumulative role in the acquisition and retention of knowledge

(Rolfhus \& Ackerman, 1999; von Stumm \& Ackerman, 2013). In this context, the significance of openness/intellect, a personality trait that describes the tendency to be imaginative, original, reflective, curious, as well as intellectually and culturally interested, is also discussed (Goldberg, 
1992; McCrae \& Costa, 1997). As the compound label suggests, it comprises two facets, which are differentially related to knowledge: While openness for fantasy, aesthetics, or feelings have low or near-to-zero correlations with gc (von Stumm \& Ackerman, 2013), the facets with an intellectual connotation such as the ideas facet show substantial correlations with gc (Ashton et al., 2000; von Stumm \& Ackerman, 2013). A proposed explanation for this association is that intellectually open individuals are more likely to seek out new situations in which they are, in turn, more likely to be confronted with new information they contemplate and ultimately acquire (see also the intellect framework of Mussel, 2013). Thus, intellectual openness is deemed to increase the likelihood of self-motivated learning and the active search for learning opportunities (Ackerman, 1996).

Investment theories have proposed that openness/intellect determines the amount of energy put into intellectual activities, while interests (e.g., Holland, 1997) determine the direction in which this energy is steered (Ackerman, 2000; Ziegler et al., 2018). This position assumes that openness/intellect as a personality trait leads to relatively undirected knowledge acquisition in a variety of different domains (e.g., through reading about various topics). Therefore, openness/intellect would be expected to correlate positively with knowledge in a broad variety of domains but, due to its undirected nature, not be expected to cause a differentiation of knowledge. This assumption presupposes a separation of openness and (predominantly academic) interests, that is difficult to maintain empirically because of sizeable correlations between both constructs (McKay \& Tokar, 2012). It is therefore questionable if openness really works in such an indiscriminate fashion. In contrast, one might argue that intellectual openness is inevitably directed towards knowledge domains one is interested in. To the extent that openness/intellect is directed towards specific topics, one should also find increasing 
differentiation (i.e., decreasing correlations between knowledge domains) with increasing levels of openness/intellect. Whether or not openness/intellect affects both the mean and covariance structure of knowledge is an empirical question and the current study aims to provide a first test in this regard.

\section{Methodological Considerations in the Investigation of Age Differentiation}

The previous sections have outlined influential theories about the structural development of declarative knowledge and plausible mechanisms and constructs that might cause a differentiation of knowledge with age. To convincingly test such hypotheses empirically, several important aspects regarding measurement, sample, and analytic strategy need to be considered. From a measurement point of view, to allow for differentiation, declarative knowledge must be covered with adequate breadth and depth. Thereto, the items must reflect a broad range of knowledge domains. In the same vein, the persons assessed with such a knowledge test should be broadly sampled from the population for which inferences are to be drawn, specifically with regards to salient stratification characteristics such as the educational and vocational background. Most prominently, any study examining are-related differences and differentiation presupposes a sufficiently large and fine-grained age distribution across adult life to detect the onset of change with decent statistical power.

From a statistical point of view, the age-related differentiation hypothesis translates into the hypothesis that correlations of different domains from a comprehensive declarative knowledge assessment decrease as a function of the continuous moderator variable age. Obviously, attention must be paid that potential differences in the covariance structure do not trace back to methodological shortcomings such as reliability problems, floor or ceiling effects. Given the positive manifold across declarative knowledge domains, the construct is best modeled 
in a higher-order factor model (Steger et al., 2019). The prevalent investigation of differentiation by means of the strength of the first unrotated eigenvalue or the magnitude of g-factor loadings across age is therefore insufficient. Molenaar and colleagues (2010) outlined how differentiation of cognitive abilities can manifest in specific measurement parameters. For example, differentiation can be reflected in lower factor loadings on the higher-order factor and with increasing (residual) variances of the first-order factors. Thus, studying differentiation with age requires the application of methods that allow testing for measurement invariance of parameters in factor analytic models across a continuous moderator (e.g., Hildebrandt et al., 2009; Molenaar, 2020; Tucker-Drob, 2009). Moreover, it is important to distinguish between research questions tapping traditional knowledge trajectories (i.e., mean-level) and research questions concerning differentiation (i.e., variance-covariance-level). These questions are not completely independent of each other because the invariance of the variance-covariance structure is a necessary but not sufficient prerequisite for the interpretation of potential mean level differences. Therefore, the question whether declarative knowledge is structurally invariant across age is also relevant to the question if mean comparisons across age are legitimate (Horn \& McArdle, 1992).

\section{Evidence for Age-Related Differences in the Mean and Covariance Structure of Gc}

Studies on the mean structure of gc generally report steady increases until middle adulthood, followed by maintenance across the majority of adult lifespan. Such trajectories contrasts mean trajectories of most other cognitive abilities (e.g., reasoning, memory, mental speed) which are characterized by steep mean-level increases until early adulthood, followed by a steady decline (e.g., Baltes et al., 1999; Li et al., 2004; McArdle et al., 2002; Tucker-Drob, 2009; Tucker-Drob \& Salthouse, 2008). Therefore, unlike gf, age does not seem to have a detrimental effect on the level of gc. If gc is conceptualized as declarative knowledge instead of 
being limited to language abilities or vocabulary, a stagnation from young adulthood onwards seems implausible, at least until old age, and empirical evidence suggests that gc might be exempted from the so-called terminal decline (Rönnlund et al., 2005). With advancing age, the rate of learning might be slower than during adolescence and young adulthood, but one would still expect that new knowledge can be acquired throughout the entire life (Boulton-Lewis, 2010).

In contrast to mean trajectories, research on differences in the internal structure of $\mathrm{gc}$ is rare. There is a huge body of literature dealing with age-associated differences in the structure of general cognitive ability (see Hartung et al., 2018; Zelinski \& Lewis, 2003 for overviews), but in such studies gc is either correlated with other broad ability factors or serves as an indicator of a higher-order $\mathrm{g}$ factor. Such studies provide some useful, yet limited, information about the structural development of gc. For example, Tucker-Drob and Salthouse (2008) investigated age trends in a model of five correlated ability factors (i.e., fluid reasoning, spatial reasoning, verbal knowledge, processing speed, and episodic memory). Performing multiple-group confirmatory factor analyses with linear and non-linear constraints, they found largely invariant factor loadings of four vocabulary tests on a common gc factor across seven age groups between 24 and 92 years, arguing that no evidence for age differentiation of vocabulary knowledge could be established. Tucker-Drob (2009) examined age-associated differences in the structure of a higher-order factor model of cognitive ability in a sample aged 4 to 101 . Therein, gc was measured with a test of lexical knowledge, a test of language development, and a test of attention and general information. However, Tucker-Drob's focus was on the loadings of seven first-order factors on a second-order g-factor. In that respect, he found little evidence for age-related differentiation. Importantly, this study did not investigate lower levels within a hierarchical 
model of cognitive abilities such as the structure of gc operationalized as declarative knowledge. Hartung et al. (2018) examined age-related differentiation in a correlated factor model of gf and gc. Here gc was measured with tests of oral vocabulary, reading vocabulary, and knowledge in humanities. They observed strict age invariance for the full model in a sample aged 25 to 94 , which implies that the parameters of the measurement model of gc did not differ across age either. Research that specifically addresses age-related differences in the structure of declarative knowledge using comprehensive measures of gc is sparse. In one such study, Schroeders and colleagues (2015) investigated age differentiation at the level of the three broad knowledge areas, natural sciences, humanities, and social sciences, in a sample of secondary school students attending Grades 5 to 12 . The authors found no age-related differentiation across knowledge domains and concluded that the result is in line with Cattell's (1971) argumentation that gc differentiates only after regular schooling. Therefore, they requested to extend the examination of gc differentiation to adult samples, where differentiation is plausible to assume.

\section{The Present Study}

Gc has been termed the "dark matter" of intelligence research (Ackerman, 2000). This neglect of gc also applies to the testing of age differentiation, which is surprising given the scope and relevance of such a phenomenon and the clearly formulated assumptions and mechanisms (Ackerman, 1996; Cattell, 1987). The fact that often cited phenomena are not always supported by empirical evidence, however, has recently been highlighted for the age differentiationdedifferentiation, where newer studies applying more appropriate statistical tools generally showed little evidence in its favor (Hartung et al., 2018; Molenaar et al., 2010; Tucker-Drob, 2009). Accordingly, it is important to subject the age differentiation hypothesis of declarative knowledge proposed by the investment theory to a rigorous empirical test. The current study 
aimed to test the hypothesis with a particularly comprehensive declarative knowledge test covering twelve knowledge domains and a total of 120 items. We investigated differentiation at the level of general knowledge, the level of broad knowledge areas, and also narrower knowledge domains. To overcome the issue of range-restriction of previous studies, we analyzed data from a large and heterogeneous sample with a broad and uniform age distribution covering major parts of the adult lifespan. To study differentiation across the continuous moderator age, we estimated higher-order, local structural equation models of declarative knowledge in combination with a recently introduced joint estimation approach to test for structural differentiation. Finally, we extended the main analyses by investigating how openness/intellect is related to differences in the mean and covariance structure of knowledge and how its different facets are related to knowledge across age.

\section{Method}

\section{Participants and Procedure}

Participants for the web-based study were recruited via email, social media, flyers, and the German online panel Respondi. The study was conducted according to the ethical guidelines for online studies of the German Society for Online Research (DGOF). Consent of each participant was requested in digital form on the first page of the survey and anonymity of participants was guaranteed. Ethical approval was not required as per local legislation. In total, 1,721 participants participated in the study, of which 1,629 (94.7\%) were considered in the analysis after a stepwise data cleaning procedure. Subjects were excluded due to data recording problems $(n=35)$, failed attention checks $(n=2)$, fast/careless responding $(\mathrm{n}=20)$, insufficient German skills $(n=20)$, if they were older than 70 years $(n=7)$ or if their overall score was 
below guessing probability $(n=8)$. To ensure adequate test power $(1-\beta=.80)$ for the model parameters at all focal age points, the necessary sample size was estimated a priori through a Monte-Carlo simulation using the R package simsem (version 0.5-15, Pornprasertmanit et al., 2020; see OS1 at https://osf.io/8agu9/ for comprehensive information on the power analysis). The analysis sample was balanced concerning gender $(47.3 \%$ women, $52.4 \%$ male, $0.3 \%$ diverse or did not report their gender) and highly age-heterogeneous with a largely uniform age distribution between 18 and 70 years $(M=45.3$ years, $S D=14.7$, see OS2 at https://osf.io/9nkqv/). We chose age 70 as the upper limit for our study because mild cognitive impairment and dementia are increasingly prevalent afterwards (Matthews et al., 2013) and presumably the online sample is getting more and more selective with increasing age. These conditions in old age potentially affect the level and structure of declarative knowledge in various ways, and we were not able to control for it in our online study. Concerning the highest educational attainment, $31.9 \%$ reported having a university degree, $27.8 \%$ completed some sort of vocational training (abgeschlossene Berufsausbildung), 19.0\% reported having a degree from an intermediate track school (Realschulabschluss), 15.8\% reported having a degree from an academic track school (Abitur), 5.2\% reported having a degree from an elementary or vocational track school (Grund-/Hauptschulabschluss), and 6 subjects did not indicate their educational attainment. The majority of the participants reported currently working as employees in the private sector $(52.8 \%)$, followed by $17.3 \%$ pensioners, $10.7 \%$ pupils/students, $6.4 \%$ selfemployed, 3.4\% civil servants, and 9.4\% others (e.g., unemployed, on maternity leave or no response; see OS3 https://osf.io/xhfgn/ for the distribution of occupational areas).

\section{Measures}

\section{Declarative Knowledge}


Declarative knowledge was measured with 120 knowledge items (see OS6 at https://osf.io/fqztp/). Items were sampled from a larger item pool (Steger et al., 2019) in order to cover 12 knowledge domains (law, politics, economics, chemistry, mathematics, physics, nutrition, health, medicine, arts, literature, music), nested in 4 broader knowledge areas (social sciences, natural sciences, life sciences, humanities), with adequate breadth (number of different domains) and depth (range of item difficulties within each domains). Items were selected according to the recommendations of Schneider \& McGrew (2012, p. 122); that is, an easy item "should reveal a serious knowledge deficit if not answered correctly", and a hard item is "not merely obscure. It should reflect uncommon wisdom [...] or it should be associated with deep knowledge of important aspects of one's local culture.” Importantly, the items tapped both knowledge that was likely acquired in the German school curriculum and knowledge that was most certainly acquired outside of school (i.e., through higher education, profession, or in the leisure time). Each domain was measured with ten multiple-choice items. Items were presented in random order for each participant.

\section{Openness/Intellect}

Openness/intellect was measured using an abbreviated scale of the Trait-Self Description Inventory (Olaru et al., 2015), measuring the three facets "Intellectual openness" (e.g., "I like to spend time in intellectual discussions with my friends."), "Scientific openness" (e.g., "I am fascinated with the theory of evolution.") and "Reflective openness" (e.g., "I spend a lot of time analyzing my internal feelings.”) with 3 items each (see OS6 at https://osf.io/fqztp/). Participants responded on a 5-point likert scale (responses coded from 1-5) from "strongly disagree" to "strongly agree".

\section{Statistical analysis}


Confirmatory factor analyses were performed with the lavaan package (version 0.6-7, Rosseel, 2012) in $R$ (version 4.0.0, R Core Team, 2020). Local structural equation models were estimated with the sirt package (version 3.9-4, Robitzsch, 2020). The Weighted Least Squares Mean and Variance adjusted (WLSMV) estimator, which is appropriate for categorical data (Beauducel \& Herzberg, 2006), was used for all item-level models. Model fit was considered good with $\mathrm{CFI} \geq .96$ and RMSEA $\leq .05(\mathrm{Yu}, 2002)$. Once measurement models were established, proportion correct scores were used as indicators in all subsequent analyses (Little et al., 2002). Latent models with continuous indicators were estimated using the Maximum Likelihood (ML) estimator; model fit was considered good with fit indices of CFI $\geq .95$ and RMSEA $\leq .06$ (Hu \& Bentler, 1999). Reliability was estimated with Cronbach's $\alpha$ and McDonald's $\omega$ (1999). We provide data and annotated syntax for all analyses on a repository of the Open Science Framework: https://osf.io/46gh7/.

\section{Local Structural Equation Models}

Usually, the influence of context variables on parameters in a structural equation model is studied with categorical moderator variables applying multiple-group confirmatory factor analysis (MGCFA) analysis. However, in the case of aging/developmental research this procedure artificially dichotomizes the continuous context variables age. Apart from a loss of information, this also aggravates an adequate understanding of the magnitude, onset, and course of age-associated differences. Several alternative approaches have been proposed to circumvent this problem (e.g., Hildebrandt et al., 2009; Molenaar, 2020; Tucker-Drob, 2009). In Local Structural Equation Models (LSEM; 2009), observations of a traditional SEM are weighted according to the distance between their specific value on the moderator variable and a focal point. A series of SEMs is then estimated for each focal point, providing a gradient of model 
parameters along manifestations of the moderator variable. This approach has several advantages over the traditional MGCFA: It avoids artificial dichotomization of continuous variables, it drastically reduces the necessary sample size as each observation is considered in every model (with varying weight), and it produces non-parametric age-trajectories and is thus more flexible than parametric approaches when the relationships between variables are unknown. Thus, LSEMs are ideally suited to investigate age-related differences in latent variables and also have been successfully applied for this purpose (Hartung et al., 2018, 2020; Hildebrandt et al., 2010; Olaru et al., 2019; Schroeders et al., 2015).

Moreover, we used a recently introduced joint estimation approach within the LSEM framework (Robitzsch, 2020) which allows constraining model parameters to equality across the moderator. This enables to study parameter trajectories by means of inferential statistics and to apply established concepts of measurement invariance. When the joint estimation procedure is applied, global fit indices are provided instead of fit indices for each LSEM. Accordingly, measurement invariance can be evaluated by comparing increasingly constrained models, similar to the procedure in MGCFA, and statistical inference can be conducted via bootstrapping (Olaru et al., 2020; Olaru \& Allemand, in press; but see also Molenaar, 2020, for an alternative approach to invariance testing with a continuous moderator).

\section{Results}

\section{Descriptive Results}

Descriptive statistics and measurement models for declarative knowledge and openness/intellect are reported in Table 1. Knowledge items covered the complete difficulty range, both across knowledge areas and domains (range $=.24-.94)$. The average item-total 
correlation was .38 , with a range from .08 to .61 . Fit indices for unidimensional models of the knowledge areas were generally good. Although CFI values for the domains Nutrition and Law fell below the recommended cutoff values, we refrained from data-driven model optimization. McDonalds $\omega$ ranged between .60 (Health) and .81 (Art). A comprehensive correlation matrix of all scales is provided in the Appendix A. 


\section{Table 1}

Descriptive Statistics, Model Fit, and Reliability Estimates of Knowledge and Openness/Intellect Measures

\begin{tabular}{|c|c|c|c|c|c|c|c|c|c|c|c|}
\hline Scale & $M$ & $S D$ & skew. & kurt. & $\chi^{2}$ & $d f$ & CFI & \multicolumn{2}{|c|}{ RMSEA [CI90\%] } & $\alpha$ & $\omega$ \\
\hline Declarative knowledge $^{a}$ & .57 & .14 & 0.15 & -0.60 & 248.6 & 50 & .97 & .05 & {$[.04, .06]$} & .96 & .89 \\
\hline \multicolumn{12}{|l|}{ Social Sciences } \\
\hline Law & .64 & .20 & -0.28 & -0.45 & 84.1 & 35 & .93 & .03 & {$[.02, .04]$} & .66 & .66 \\
\hline Politics & .55 & .20 & 0.21 & -0.44 & 50.1 & 35 & .98 & .02 & {$[.00, .03]$} & .65 & .66 \\
\hline Economics & .60 & .21 & -0.07 & -0.73 & 96.4 & 35 & .96 & .03 & {$[.03, .04]$} & .76 & .77 \\
\hline \multicolumn{12}{|l|}{ Natural Sciences } \\
\hline Chemistry & .48 & .24 & 0.31 & -0.72 & 104.0 & 35 & .97 & .03 & {$[.03, .04]$} & .78 & .79 \\
\hline Mathematics & .47 & .23 & 0.40 & -0.51 & 64.7 & 35 & .98 & .02 & {$[.01, .03]$} & .78 & .78 \\
\hline Physics & .57 & .21 & 0.08 & -0.68 & 75.5 & 35 & .96 & .03 & {$[.02, .03]$} & .69 & .70 \\
\hline \multicolumn{12}{|l|}{ Life Sciences } \\
\hline Nutrition & .59 & .20 & -0.12 & -0.48 & 154.8 & 35 & .88 & .05 & {$[.04, .05]$} & .71 & .72 \\
\hline Health & .60 & .19 & -0.28 & -0.32 & 36.0 & 35 & 1.00 & .00 & {$[.00, .02]$} & .59 & .60 \\
\hline Medicine & .62 & .20 & -0.13 & -0.51 & 61.8 & 35 & .98 & .02 & {$[.01, .03]$} & .73 & .74 \\
\hline \multicolumn{12}{|l|}{ Humanities } \\
\hline Art & .52 & .24 & 0.18 & -0.75 & 72.5 & 35 & .98 & .03 & {$[.02, .03]$} & .80 & .81 \\
\hline Literature & .57 & .22 & 0.10 & -0.74 & 117.1 & 35 & .96 & .04 & {$[.03, .05]$} & .79 & .79 \\
\hline Music & .58 & .22 & -0.10 & -0.70 & 60.6 & 35 & .99 & .02 & {$[.01, .03]$} & .76 & .77 \\
\hline Openness/Intellect & 3.40 & .64 & -0.39 & 0.29 & 186.0 & 36 & .96 & .06 & {$[.06, .07]$} & .78 & .76 \\
\hline Intellectual $^{\mathrm{b}}$ & 3.73 & .82 & -0.54 & 0.29 & & & & & & .73 & .74 \\
\hline Reflective $^{\mathrm{b}}$ & 3.03 & .83 & -0.12 & -0.16 & & & & & & .62 & .66 \\
\hline Scientific $^{\mathrm{b}}$ & 3.44 & .85 & -0.43 & 0.15 & & & & & & .74 & .75 \\
\hline
\end{tabular}


Note. $N=1,629 . \mathrm{M}=$ mean, $\mathrm{SD}=$ standard deviation, skew. = skewness; kurt. = kurtosis; $\mathrm{CFI}=$ comparative fit index, $\mathrm{RMSEA}=$

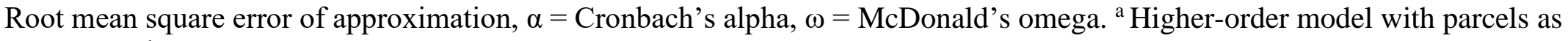
indicators. ${ }^{\mathrm{b}}$ Model fit is not reported because the models with three indicators are just identified. 
A parallel analysis of the 12 knowledge domains suggested four factors and an exploratory factor analysis with promax rotation supported the theorized assignment of knowledge domains to broader knowledge areas (see the analysis output "models" at https://osf.io/9qy5s/). Accordingly, a higher-order model of declarative knowledge with a general factor at the apex, four first-order factors reflecting the broad knowledge areas and twelve indicators based on narrower knowledge domains (Figure 1) fit the data well: $\chi^{2}(50)=248.6, p<$ $.01 ; \mathrm{CFI}=.97 ; \mathrm{RMSEA}=.05$. In comparison, a more parsimonious one-factor model did not explain the observed data adequately: $\chi^{2}(54)=1,425.7, p<.001, \mathrm{CFI}=.82, \mathrm{RMSEA}=.12$.

\section{Figure 1}

\section{Measurement Model of Declarative Knowledge}

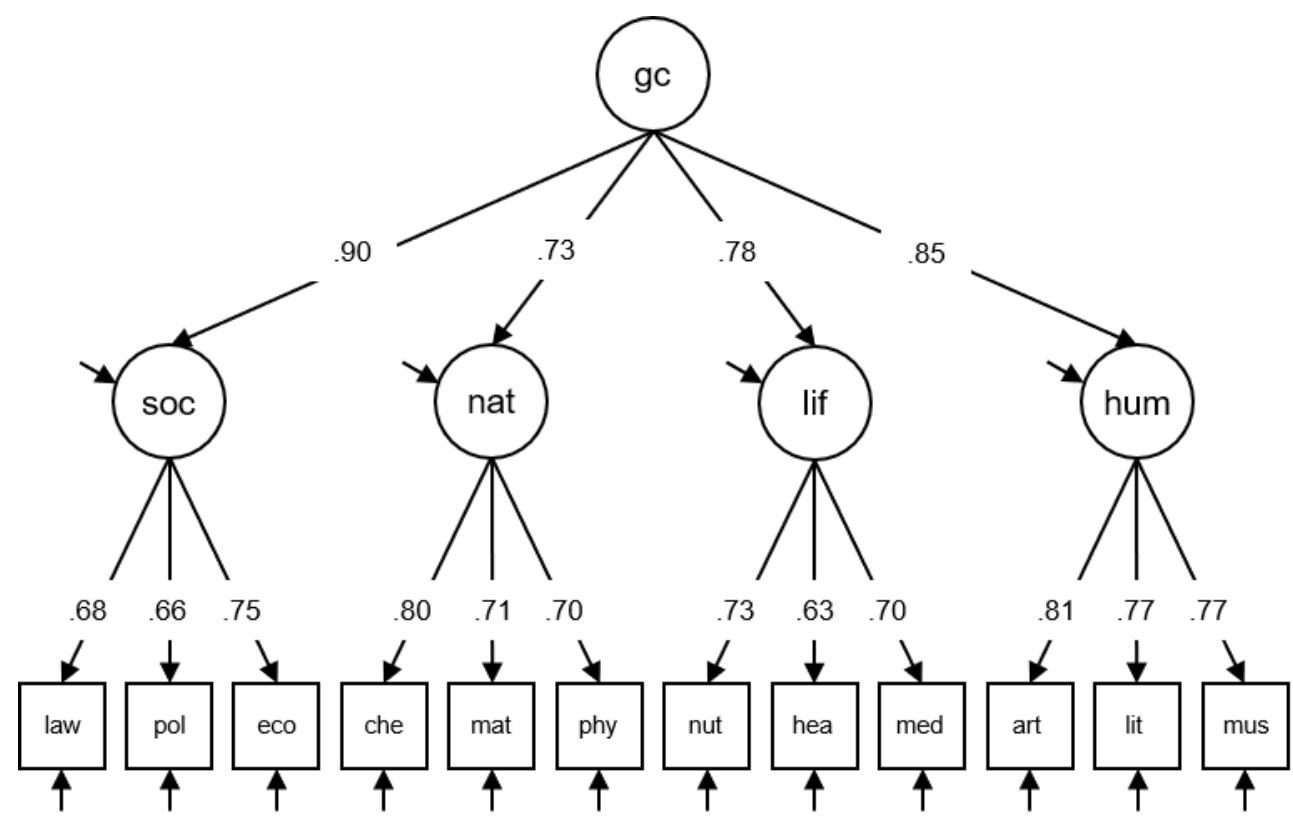

Note. Standardized parameter estimates of the second-order factor model of declarative knowledge are based on the entire sample. $n=1,629 ; \chi^{2}(50)=248.6, p<.01 ; \mathrm{CFI}=.97$; $\mathrm{RMSEA}=.05 . \mathrm{Gc}=$ crystallized intelligence, $\operatorname{soc}=$ social sciences, nat $=$ natural sciences, lif $=$ life sciences, hum $=$ humanities, law $=$ law, pol $=$ politics, eco $=$ economics, che $=$ chemistry, mat $=$ mathematics, phy $=$ physics, nut $=$ nutrition, hea $=$ health, med $=$ medicine, art $=$ arts, lit $=$ literature, mus $=$ music. 


\section{Age differentiation}

To test the age differentiation hypothesis, we estimated the higher-order model in 26 locally weighted age samples with focal points set to every two years between 20 and 70 years. The effective sample size was sufficient at all focal age points $(\min .=274)$. Increasingly strict equality constraints were imposed on the model parameters in a sequential procedure to test violations of measurement invariance (i.e., $\Delta C F I \geq .01$, Meade \& Lautenschlager, 2004). To facilitate the distinction between results concerning differences in the covariance structure and differ in the mean structure, we altered the sequence of model tests proposed by Chen et al. (2005, see Table 2); that is, we tested for first- and second-order factor loadings and residual variances of the observed and first-order factors prior to testing for differences in the intercepts of the observed variables and the first-order factor means.

Table 2

Testing Measurement Invariance of Second-Order Factor Models

\begin{tabular}{lccccccc} 
& $\begin{array}{l}\text { First-order } \\
\text { factor } \\
\text { loadings }\end{array}$ & $\begin{array}{l}\text { Second- } \\
\text { order } \\
\text { factor } \\
\text { loadings }\end{array}$ & $\begin{array}{l}\text { Residual } \\
\text { variances } \\
\text { of obs. } \\
\text { variables }\end{array}$ & $\begin{array}{l}\text { Variances } \\
\text { of first- } \\
\text { order } \\
\text { factors }\end{array}$ & $\begin{array}{l}\text { lntercepts } \\
\text { of obs. } \\
\text { variables }\end{array}$ & $\begin{array}{l}\text { First-order } \\
\text { factor } \\
\text { means }\end{array}$ & $\begin{array}{l}\text { Second- } \\
\text { factor } \\
\text { mean }\end{array}$ \\
\hline M1 & $*$ & $*$ & $*$ & $*$ & $*$ & F0 & F0 \\
M2 & FE & $*$ & $*$ & $*$ & $*$ & F0 & F0 \\
M3 & FE & FE & $*$ & $*$ & $*$ & F0 & F0 \\
M4 & FE & FE & FE & $*$ & $*$ & F0 & F0 \\
M5 & FE & FE & FE & FE & $*$ & F0 & F0 \\
M6 & FE & FE & FE & FE & FE & F0/* & F0 \\
M7 & FE & FE & FE & FE & FE & F0 & F0/* \\
\hline
\end{tabular}

Note. The asterisk (*) indicates that the parameters are freely estimated. FE $=$ parameters are fixed to equality across all focal points; $\mathrm{F} 0=$ parameters are fixed at 0 at all focal points. $\mathrm{F} 0 / *=$ parameters are fixed at 0 at the first focal point and freed in all others. 
Table 3 summarizes the results of the invariance tests of declarative knowledge across age. In the first step, a baseline model (M1) was fit where all model parameters were freely estimated. Because the model fit the data well, it can be assumed that declarative knowledge had the same general structure across the entire age range. A visual inspection of the age-gradients in factor loadings (Figure 2) suggested little variation over age.

\section{Figure 2}

Age-Gradients of $1^{\text {st }}$ - and $2^{\text {nd }}$-Order Factor Loadings 

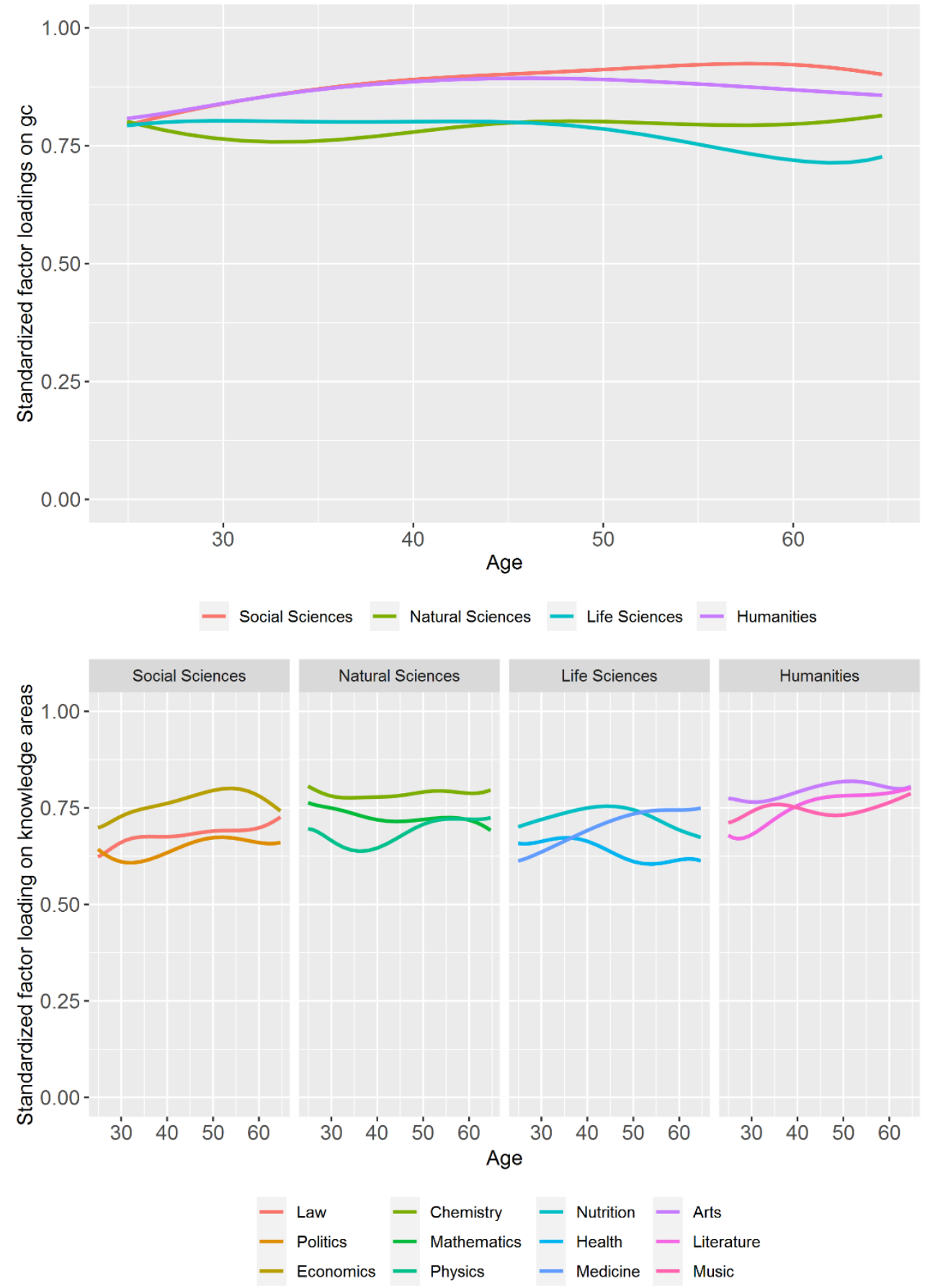

Note. Model parameters from a LSEM without constraints on model parameters across focal age points. Effective sample size $=274.15-548.54$. CFI $=.948-.971$; RMSEA $=.052-.067$.

To formally test for age-related differences in the factor loadings, we constrained the first-order loadings (M2) and second-order loadings (M3) to equality across the age range in two 
consecutive steps. Neither set of constraints on the loadings led to a noticeable loss in model fit. Therefore, factor loadings did not vary systematically as a function of age. In steps 4 and 5, equality constraints were imposed on the residual variances of the observed variables (M4) and the variances of the first-order factors (M4). Increases in the variances over age - irrespective of the level they might occur at - would indicate that that the general factor captures less variance of the indicators, which would signal differentiation. However, neither set of constraints led to a significant loss in model fit, indicating that the variance captured by the general factor did vary systematically across the age range. In sum, the stepwise model tests provided no evidence of structural differentiation of the investigated model across age.

While differences in the mean structure are not at the center of our interest, as they are not indicative of structural differentiation, they are a necessary prerequisite for the interpretation of mean trajectories prevalent (e.g., Wicherts \& Dolan, 2010). In M6, the intercepts of the observed variables were constrained to equality, which led to a small, but meaningful loss in model fit $(\triangle \mathrm{CFI}=.012)$. Exploratory investigations of the unconstrained intercept trajectories in M5 indicated that the main source of misfit originated from the knowledge domains of the humanities factor (arts, literature, music), which showed substantial increases across age (see OS4 at https://osf.io/g7kw9/). Imposing equality constraints on the first-order factor means in M7 led to a further decline in model fit $(\Delta \mathrm{CFI}=.034)$. In sum, the mean structure partially differs across age which limits the comparability of mean scores across age.

\section{Table 3}

Summary of Fit Statistics for Measurement Invariance Tests of Declarative Knowledge Over Age

\begin{tabular}{llcc}
\hline Model & Constraints & CFI $(S E)$ & RMSEA (SE) \\
\hline M1 & None & $.980(.005)$ & $.042(.004)$ \\
M2 & First-order factor loadings & $.980(.005)$ & $.039(.004)$ \\
M3 & M2 and second-order factor loadings & $.980(.005)$ & $.039(.004)$
\end{tabular}


M4 M3 and residual variances of obs. variables $\quad .980(.006) \quad .035(.004)$

M5 M4 and first-order factor variances $\quad .981(.005) \quad .034(.003)$

M6 M5 and intercepts of obs. variables $\quad .969(.006) \quad .041(.003)$

M7 M6 and means of first-order factors $\quad .935(.008) \quad .058(.003)$

Note. CFI = comparative fit index; RMSEA = root mean squared error of approximation; $S E=$ standard error. Standard errors computed via bootstrapping in 100 samples.

\section{Openness/intellect differentiation}

Prior to further analyses involving openness/intellect, we tested the age-invariance of the construct. A series of model tests comparable to the ones reported above indicated strict measurement invariance of a correlated factor model with three parcels as indicators of the three openness/intellect facets (see OS5 at https://osf.io/b6pq2/). Accordingly, we proceeded to investigate potential associations between trait levels of openness/intellect and the mean and covariance structure of knowledge. To this end, we studied differentiation across $z$-standardized openness/intellect scores. More specifically, focal points were set between -2 and 2 with increments of $1 / 3$ to ensure adequate sample sizes at each focal point $(\min =130)$. The sequence of model tests was identical to the age-related analyses. The knowledge model fit well along the entire openness/intellect-continuum and invariance tests indicated that all model parameters could be constrained to equality up to the most restrictive invariance model without meaningful deterioration of model fit (Table 4). Thus, higher levels of openness/intellect were not associated with more differentiated knowledge structures.

\section{Table 4}

Summary of Fit Statistics for Measurement Invariance Tests of Declarative Knowledge Across Openness/Intellect

\begin{tabular}{llcc}
\hline Model & Constraints & CFI (SE) & RMSEA (SE) \\
\hline M1 & None & $.979(.005)$ & $.042(.004)$ \\
M2 & First-order factor loadings & $.982(.005)$ & $.037(.004)$ \\
M3 & M2 and second-order factor loadings & $.983(.006)$ & $.035(.004)$
\end{tabular}


M4 M3 and residual variances of obs. variables $\quad .985(.005) \quad .030 .003)$

M5 M4 and first-order factor variances $\quad .985(.006) \quad .029(.004)$

M6 M5 and intercepts of obs. variables $\quad .985(.006) \quad .028(.003)$

M7 M6 and means of first-order factors $\quad .985(.005) \quad .027(.003)$

Note . CFI = comparative fit index; RMSEA = root mean squared error of approximation; $S E=$ standard error. Standard errors computed via bootstrapping in 100 samples.

\section{Association of openness/intellect facets with declarative knowledge}

Openness/intellect was correlated with knowledge ( $r=.39$ in the overall sample) but was not associated with a differentiation of the knowledge structure. To investigate differential associations of the three openness/intellect facets and knowledge across age, we also estimated three separate LSEMs in which each openness/intellect facets predicted the higher-order factor of declarative knowledge. The age-trajectories of the standardized regression coefficients are depicted in Figure 3. The results are in line with the extant literature, that is, intellectual openness and scientific openness (both close to the ideas facet of the NEO-PI-R; Costa \& McCrae, 2008) significantly predicted knowledge while reflective openness (closer to the feelings and aesthetics facets of the NEO-PI-R) did not. Interestingly, the association of intellectual openness with knowledge increased from age 45 onwards, which might indicate a beneficial effect of intellectuality on knowledge development or preservation.

\section{Figure 3}

Standardized Regression Coefficients of Openness/Intellect Facets on Declarative Knowledge 

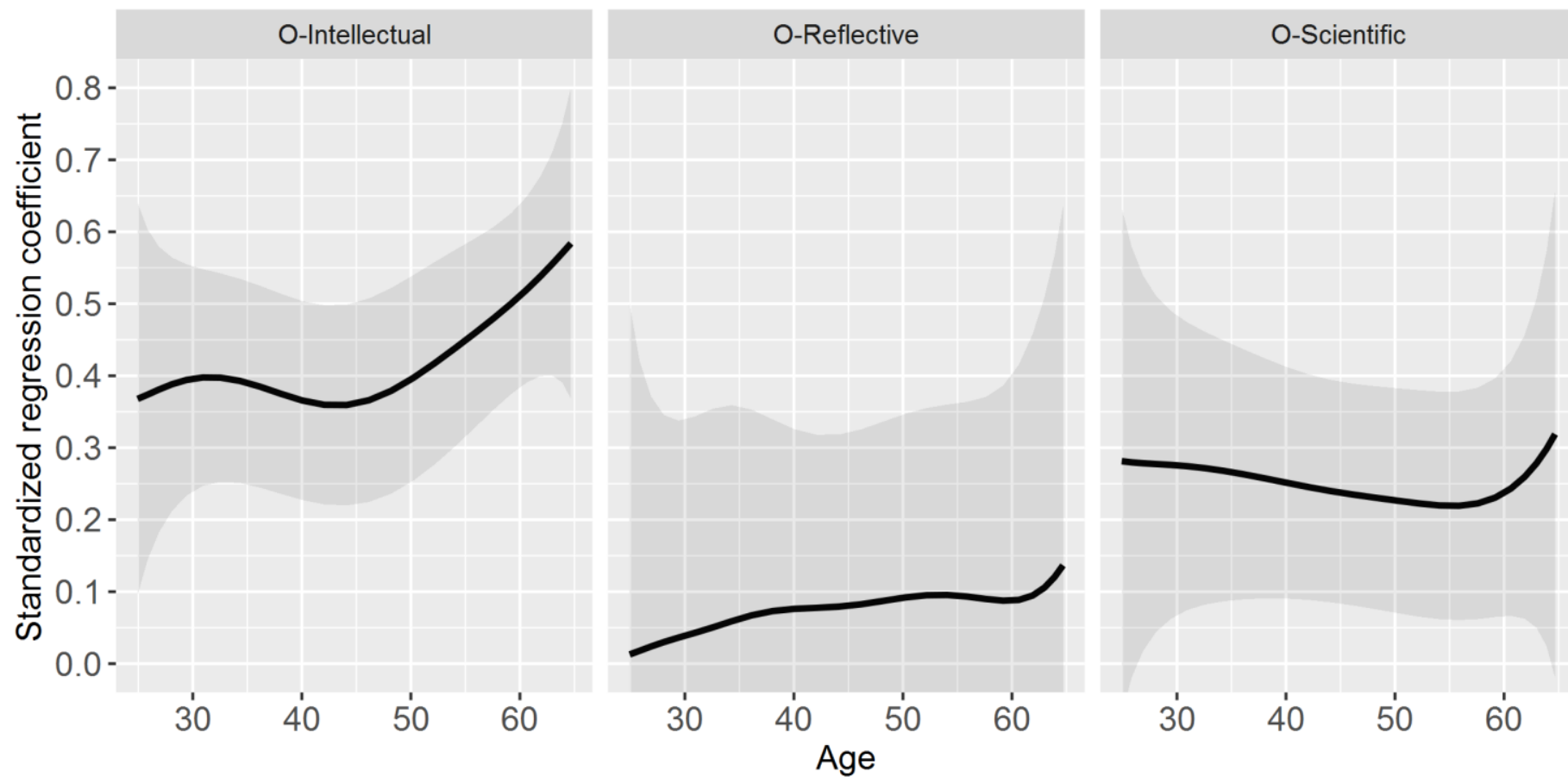

Note. Standardized regression coefficients from three separate latent factor models. The grey ribbon indicates the bootstrapped $95 \%$ confidence interval. Effective sample size $=274.15-$ 548.54 .

\section{Discussion}

The age differentiation hypothesis of declarative knowledge predicts that knowledge starts to differentiate (at the latest) after compulsory school, when different vocational paths, tertiary education, or hobbies start to individualize the acquisition of increasingly diverse and specialized knowledge (Ackerman, 1996; Cattell, 1987). To test this hypothesis empirically, we investigated whether the parameters of a higher-order model of declarative knowledge systematically varied as a function of age. Constraining the structural parameters of the knowledge model to equality across age did not lead to a significant deterioration in model fit. In contrast to theories about the differentiation of declarative knowledge, the results indicate no differences in the structure of declarative knowledge until the age of 70 . Concerning the mean structure, we observed slight increases in adulthood, with the strongest increases in the 
humanities and slight decreases in the natural sciences that leveled out on an aggregate level. Positive associations between openness/intellect and knowledge have occasionally fueled theories about causal relations between both constructs (Ackerman, 1996; Ziegler et al., 2018). Our results replicated the correlation of different facets of openness/intellect with knowledge and demonstrated that higher levels of openness/intellect were not associated with more differentiated knowledge structures.

\section{Age Invariance}

In the current study, the measurement of declarative knowledge covered a variety of domains such as mathematics, medicine, and arts. Also, the range of item difficulties indicated an adequate depth within these knowledge domains. Given the educational and vocational diversity of the sample, one could expect that subjects were exposed to and acquired very different knowledge along their individual life and learning trajectories. Further, the age distribution was very broad and largely uniform, which ensured sufficient measurement precision to detect agerelated knowledge differentiation in adulthood. Statistically speaking, the models allowed to test all relevant parameters in the higher-order latent factor model along the continuous moderator at all investigated age points, avoiding prevalent problems with manifest analyses and artificial categorization of the moderator age, which is continuous in nature (Hildebrandt et al., 2016; MacCallum et al., 2002). Together with the evidence concerning the structural invariance of knowledge at school age (Schroeders et al., 2015) and earlier evidence for the lack of ageassociated differences in adulthood (e.g., Hartung et al., 2018; Tucker-Drob \& Salthouse, 2008), we argue that the current study provides strong additional evidence against the age differentiation hypothesis of declarative knowledge (Ackerman, 1996; Cattell, 1987). At the very least, age differentiation does not manifest itself as readily and invariably as suggested by investment 
theories. Instead, a hierarchical model with a strong common factor represented general declarative knowledge well across the range of the adult lifespan studied here.

\section{The Dimensionality of Knowledge and Its Implications for the Differentiation Hypothesis}

For declarative knowledge, the breadth and depth of the assessment hinges on the compilation of item sets. Thus, item sampling issues are even more pressing and crucial than for other psychological constructs (Cattell, 1987; Schroeders et al., 2021; Schroeders, Wilhelm, et al., 2016; Steger et al., 2019). Some of the domains are part of school curricula, for example, for the domains of the natural sciences. Other domains including law, economics, health, and medicine are not part of compulsory education in Germany. Thus, the content coverage of the present assessment is broad and comprises widely acknowledged aspects of general education rather than highly specialized knowledge or expert knowledge that is bound to specific learning opportunities. With 120 items across 12 knowledge domains, it follows operationalizations of declarative knowledge in similar studies in terms of content but is broader than several earlier efforts that specialized on specific content domains (e.g., health-related knowledge in Beier \& Ackerman, 2003). Previous studies with a comparable broad assessment of knowledge have been limited by small and selective samples (e.g., Ackerman, 2000) or massive missing data due to an ambulatory assessment approach (Steger et al., 2019), which aggravates analyses for testing the differentiation hypothesis rigorously. We think that our broad assessment of knowledge is better suited to test the differentiation hypothesis than narrowly circumscribed units of knowledge because there is a higher potential to detect differentiation in a heterogeneous adult sample (concerning educational, ethnic, or geographical background).

Alternative operationalizations of declarative knowledge might deliver different results concerning the question of differentiation. Whether or not differently sampled domains deliver 
deviating conclusions concerning differentiation is subject to future research. For example, oversampling non-scholastic knowledge (e.g., gardening), highly specialized knowledge (e.g., quantum physics), or current event knowledge (e.g., stars and celebrities) might deliver different results concerning differentiation. Common sense and lived experience certainly suggest idiosyncratic knowledge profiles in specialized domains that are affected by vocational or more idiosyncratic interests. There are several reasons why we remain sceptical that the effects are fundamentally different from those reported here. First, the theoretical propositions about different types of knowledge such as scholastic vs. non-scholastic knowledge (Cattell, 1987), vocational vs. avocational knowledge (e.g., Ackerman, 1996) or "comprehension knowledge vs. general (domain-specific) knowledge" (Schneider \& McGrew, 2012) are problematic, because they are insufficiently endorsed by empirical evidence. Additionally, these distinctions are often blurry when it comes to classifying items in one domain or another. For example, what was niche knowledge and part of vocational training several years ago might now by widely disseminated (e.g., what is a USB port?). To infer from the content of an item to the opportunity or context at which the content is learned is fuzzy and opaque. For instance, although there are age-related differences in the solution probabilities for specific items, there is no convincing classification of items based on such information (Schroeders et al., 2021). Second, regarding a separation of general and specialized knowledge, recent research based on very broad item samples suggested that even large numbers of highly heterogeneous knowledge domains can be described satisfactorily with a strong general factor in a hierarchical model (Schipolowski et al., 2014; Steger et al., 2019). In such models, there is only limited evidence for domain specificity. Also, domain-specific knowledge usually shows high correlations with a general knowledge factor (e.g., environment-specific knowledge correlates $r=.93$ with general knowledge; Geiger et al., 
2019). These findings make it questionable whether or not types of knowledge can be satisfactorily discriminated and whether or not they are subject to differentiated age trajectories.

Given the sparse evidence concerning differentiation of knowledge we cannot exclude an evidence-of-absence scenario if no differentiation is found in an inevitably limited single study. Obviously, this situation is common for empirically working critical rationalists. We, therefore, look forward to further studies that sample content differently and succeed in showing idiosyncratic profiles and differentiation along with predictors of both phenomena. For the time being, we suggest - according to Ockham's razor — that given the absence-of-evidence in the present compilation across age or openness/intellect, this will also apply to other compilations of items. A simple reason why we did not find differentiation might therefore be that, as long as gc is operationalized as the "breadth and depth of knowledge [...] of the dominant culture" (Horn, 2008, p. 197), and is measured in heterogeneous cross-sectional samples, age-related differences are constrained to the mean structure rather than the covariance structure-concepts that are sometimes not kept as neatly apart as they should be. Whereas age-related differences in levels of declarative knowledge and differences across knowledge domains have repeatedly been reported (e.g., Ackerman, 2000; Schroeders et al., 2015), findings on structural differentiation are simply missing. In fact, age-associated mean differences are well-document for many psychological constructs, but we are not aware of any hypothesis of structural differentiation that has received satisfying empirical support (e.g., Breit et al., 2021; Hartung et al., 2018, 2020, 2021; Schroeders et al., 2015; Tucker-Drob, 2009).

\section{Openness Invariance}

The age-differentiation hypothesis revolves around chronological age, but the time passed since birth has no inherent explanatory power itself (Wohlwill, 1970). Instead, it is a proxy for a 
plethora of interacting processes that influence the level and structure of declarative knowledge. Given the positive associations with knowledge, openness/intellect has been proposed as a more tangible construct that might influence the development of knowledge. In the current study, we observed substantial positive correlations between openness/intellect and knowledge in combination with a strict structural invariance of knowledge across the openness/intellect continuum. Thus, higher levels of openness/intellect were associated with higher levels of knowledge but not with a more differentiated knowledge structure. These results support the perspective that openness/intellect is a general driver in the acquisition of knowledge rather than a construct that affects the direction and thereby the development of idiosyncratic structures of knowledge (Ackerman, 2000; Ziegler et al., 2018). Admittedly, the present collection of items might be unsuitable to show relations with idiosyncratic knowledge structures and measures targeted more directly and comprehensively at intellectual engagement might be better suited (Mussel, 2013).

Analyses of the association of facets of openness/intellect and knowledge replicated and extended established findings. As expected, facets with an intellectual connotation correlated moderately to strongly with knowledge, whereas the "reflective" facet of openness did not (Ashton et al., 2000; von Stumm \& Ackerman, 2013). While the correlations of scientific openness and reflective openness were largely stable across age, the correlation of intellectual openness and knowledge increased steadily from age 45 onwards. This result endorses the conclusion that intellectual openness is beneficial for knowledge in middle and old adulthood. While the increase in strength of the association is continuous and substantial, this interpretation is tentative given the cross-sectional nature of this study and the fact that other studies have so far failed to provide convincing evidence for a protective effect of openness against cognitive 
decline (see Curtis et al., 2015, for a review). Yet, these studies have generally focused on fluid abilities, which seem inevitably to decline. Please also note that the relation between age and general knowledge is small. Since everyday cognition in old age increasingly depends on knowledge and experience (Ackerman, 2000; Hertzog, 2009), further investigations of the reciprocal relationships between status and change in intellectual openness and knowledge are demanded. Such investigations of the "use it or lose it" hypothesis (Hertzog, 2009) with regards to knowledge could and should exploit the full potential of recent methodological developments (Usami et al., 2019).

\section{Implications for age-comparative research}

Sprague et al.'s (2018, p. 86) observation that “invariance of intelligence across age is often assumed but infrequently explicitly tested" also applies to crystallized intelligence. Thus, the current results are important for age-comparative research, where crystallized intelligence is to be compared across individuals of differing age. The invariance of factor loadings is a necessary precondition for the meaningful interpretation of correlations with covariates (e.g., learning outcomes or job performance) and scalar invariance is a necessary precondition for mean comparisons across participants of different age (Horn \& McArdle, 1992). The current study suggests that such correlational analyses can be valid, especially when knowledge is measured in such breadth and in such age-heterogeneous samples. Considering the item and sample effects observed in knowledge tests (Schroeders et al., 2021; Schroeders, Wilhelm, et al., 2016), however, this has to be tested with appropriate statistical methods (e.g., LSEM) for every specific compilation of declarative knowledge items.

This study focused on age differentiation, and, thus, on the variance-covariance structure of declarative knowledge. Concerning the mean structure, our results showed that constraining 
both factor means and item intercepts across the age range led to a noticeable deterioration in model fit. Accordingly, a comparison of the aggregate total knowledge score across age is not admissible. Exploratory investigations on the next subordinate level of knowledge (i.e., firstorder factors or knowledge areas), however, revealed that the primary source of misfit was the first-order factor humanities, while other knowledge areas were less affected. Our compilation of largely "classic" knowledge from the humanities (e.g., Rembrandt, Remarque, Ravel) might have captured knowledge that is not as prevalent or relevant in younger individuals. These trajectories are uniform at the next lower level, that is, for all knowledge domains within the humanities (see OS4 at https://osf.io/g7kw9/). However, recent research emphasized the importance of knowledge nuances in the assessment of declarative knowledge (Schroeders et al., 2021; Schroeders, Wilhelm, et al., 2016). In more detail, Schroeders et al. (2021) demonstrated that the majority of age variance in knowledge is located at the item-level and that these age effects are leveled out when working with increasingly aggregate scores. Thus, a less bourgeois way of measuring humanities as we did in the present study (e.g., digital art, k-pop), could be suitable to reverse the effects found here. In sum, great attention must be paid to item selection in knowledge tests in order to allow valid comparisons across individuals of differing age.

\section{Limitations and Future Directions}

Although the current study features several important strengths, we want to address three main limitations. First, in cross-sectional designs, age effects are potentially confounded with cohort effects (Baltes, 1968). For example, changes in the educational system or a "shift of mixture of areas intellectually fashionable" (Cattell, 1987, p. 149) might affect the distribution of knowledge between age groups. Long-range longitudinal studies are needed to investigate within-person developments across the lifespan but they are inherently costly and must deal with 
problems such as retest-effects and attrition (e.g., Ferrer et al., 2004; Lindenberger et al., 2002). Thus, both designs have their (dis-)advantages and sophisticated designs (e.g., multi-cohort longitudinal studies) are necessary to delineate age- and cohort-effects (Baltes, 1968), as well as potential differences in between- and within-person structures of cognitive abilities (Schmiedek et al., 2019; Voelkle et al., 2014). Second, diverging theories on the nature and structure of declarative knowledge, as well as the construct-immanent difficulty to assess it comprehensively, impact the comparability of research results and the generalizability of research findings. Recent work based on very broad item sets has substantially improved our understanding of the dimensionality of knowledge, but both empirical and theoretical work is still needed to unify competing theories and to address issues of dimensionality, item sampling and alternative measurement models. Also, more work is needed to understand determinants of knowledge acquisition, such as individual biographical experiences or the cultural environment in which one grows up and lives. In this sense, our assessment is in line with common broad operationalizations of declarative knowledge, and the empirical literature suggests little evidence for differentiation of knowledge, but it remains an empirical question if alternative compilations of declarative knowledge would yield equally unambiguous evidence for the structural invariance across age or openness/intellect. Third, research on the declarative knowledge in old and very old age is scarce and a highly interesting research avenue. More research with samples aged 70 and older should follow up on this work to examine the further course of development and to provide a more complete picture of declarative knowledge in aging.

\section{Conclusion}

The current study provided a thorough test of the age differentiation hypothesis of declarative knowledge across a large age range. The results of LSEM unequivocally refute the 
hypothesis. Instead, a broad hierarchical model of declarative knowledge was highly stable from young adulthood to old age. At the level of the mean structure, however, age differences were apparent that caution the unrestricted comparison of mean knowledge levels across different ages. Openness/intellect was associated with higher levels of knowledge but not with more differentiated knowledge structures. In conclusion, the appropriate sampling of knowledge items and domains thus seems to be a more pressing issue for age-comparative research than the alleged concern that the entire construct comes apart. 


\section{References}

Ackerman, P. L. (1996). A theory of adult intellectual development: Process, personality, interests, and knowledge. Intelligence, 22(2), 227-257. https://doi.org/10.1016/S01602896(96)90016-1

Ackerman, P. L. (2000). Domain-specific knowledge as the 'dark matter' of adult intelligence: Gf/Gc, personality and interest correlates. Journal of Gerontology, 55(2), 69-84. https://doi.org/10.1093/geronb/55.2.P69

Ackerman, P. L. (2003). Cognitive ability and non-ability trait determinants of expertise. Educational Researcher, 32(8), 15-20. https://doi.org/10.3102/0013189X032008015

Ackerman, P. L., \& Beier, M. E. (2006). Determinants of domain knowledge and independent study learning in an adult sample. Journal of Educational Psychology, 98(2), 366-381. https://doi.org/10.1037/0022-0663.98.2.366

Alexander, K. L., Entwisle, D. R., \& Olson, L. S. (2001). Schools, achievement, and inequality: A seasonal perspective. Educational Evaluation and Policy Analysis, 23(2), 171-191. https://doi.org/10.3102/01623737023002171

Ashton, M. C., Lee, K., Vernon, P. A., \& Jang, K. L. (2000). Fluid intelligence, crystallized intelligence, and the openness/intellect factor. Journal of Research in Personality, 34(2), 198-207. https://doi.org/10.1006/jrpe.1999.2276

Baltes, P. B. (1968). Longitudinal and cross-sectional sequences in the study of age and generation effects. Human Development, 11(3), 145-171. https://doi.org/10.1159/000270604 
Baltes, P. B., Staudinger, U. M., \& Lindenberger, U. (1999). Lifespan psychology: Theory and application to intellectual functioning. Annual Review of Psychology, 50(1), 471-507. https://doi.org/10.1146/annurev.psych.50.1.471

Beauducel, A., \& Herzberg, P. Y. (2006). On the Performance of Maximum Likelihood Versus Means and Variance Adjusted Weighted Least Squares Estimation in CFA. Structural Equation Modeling: A Multidisciplinary Journal, 13(2), 186-203. https://doi.org/10.1207/s15328007sem1302_2

Beier, M. E., \& Ackerman, P. L. (2003). Determinants of health knowledge: An investigation of age, gender, abilities, personality, and interests. Journal of Personality and Social Psychology, 84(2), 439-448. https://doi.org/10.1037/0022-3514.84.2.439

Beier, M. E., \& Ackerman, P. L. (2005). Age, ability, and the role of prior knowledge on the acquisition of new domain knowledge: Promising results in a real-world learning environment. Psychology and Aging, 20(2), 341-355. https://doi.org/10.1037/08827974.20 .2 .341

Boulton-Lewis, G. M. (2010). Education and learning for the elderly: Why, how, what. Educational Gerontology, 36(3), 213-228. https://doi.org/10.1080/03601270903182877

Breit, M., Brunner, M., \& Preckel, F. (2021). Age and ability differentiation in children: A review and empirical investigation. Developmental Psychology. https://doi.org/10.1037/dev0001147

Carroll, J. B. (1993). Human cognitive abilities: A survey of factor-analytic studies. Cambridge University Press. https://doi.org/10.1017/CBO9780511571312

Cattell, R. B. (1971). Abilities: Their structure, growth, and action. Houghton Mifflin.

Cattell, R. B. (1987). Intelligence: Its structure, growth and action. North Holland. 
Chen, F. F., Sousa, K. H., \& West, S. G. (2005). Teacher's corner: Testing measurement invariance of second-order factor models. Structural Equation Modeling: A Multidisciplinary Journal, 12(3), 471-492. https://doi.org/10.1207/s15328007sem1203_7

Cooper, H., Nye, B., Charlton, K., Lindsay, J., \& Greathouse, S. (1996). The effects of summer vacation on achievement test scores: A narrative and meta-analytic review. Review of Educational Research, 66(3), 227-268. https://doi.org/10.3102/00346543066003227

Costa, P. T., \& McCrae, R. R. (2008). The revised neo personality inventory (NEO-PI-R). In G. J. Boyle, G. Matthews, \& D. H. Saklofske (Eds.), The SAGE Handbook of Personality Theory and Assessment (Vol. 2, pp. 179-198). Psychological Assessment Resources.

Curtis, R. G., Windsor, T. D., \& Soubelet, A. (2015). The relationship between Big-5 personality traits and cognitive ability in older adults - a review. Aging, Neuropsychology, and Cognition, 22(1), 42-71. https://doi.org/10.1080/13825585.2014.888392

Ferrer, E., \& McArdle, J. J. (2004). An experimental analysis of dynamic hypotheses about cognitive abilities and achievement from childhood to early adulthood. Developmental Psychology, 40(6), 935-952. https://doi.org/10.1037/0012-1649.40.6.935

Ferrer, E., McArdle, J. J., Shaywitz, B. A., Holahan, J. M., Marchione, K., \& Shaywitz, S. E. (2007). Longitudinal models of developmental dynamics between reading and cognition from childhood to adolescence. Developmental Psychology, 43(6), 1460-1473. https://doi.org/10.1037/0012-1649.43.6.1460

Ferrer, E., Salthouse, T. A., Stewart, W. F., \& Schwartz, B. S. (2004). Modeling age and retest processes in longitudinal studies of cognitive abilities. Psychology and Aging, 19(2), 243-259. https://doi.org/10.1037/0882-7974.19.2.243 
Garrett, H. E. (1946). A developmental theory of intelligence. American Psychologist, 1(9), 372378. https://doi.org/10.1037/h0056380

Geary, D. C., Nicholas, A., Li, Y., \& Sun, J. (2017). Developmental change in the influence of domain-general abilities and domain-specific knowledge on mathematics achievement: An eight-year longitudinal study. Journal of Educational Psychology, 109(5), 680-693. https://doi.org/10.1037/edu0000159

Geiger, S. M., Geiger, M., \& Wilhelm, O. (2019). Environment-specific vs. General knowledge and their role in pro-environmental behavior. Frontiers in Psychology, 10, 718. https://doi.org/10.3389/fpsyg.2019.00718

Goldberg, L. R. (1992). The development of markers for the big-five factor structure. Psychological Assessment, 4(1), 26-42. https://doi.org/10.1037/1040-3590.4.1.26

Hambrick, D. Z., \& Engle, R. W. (2002). Effects of domain knowledge, working memory capacity, and age on cognitive performance: An investigation of the knowledge-is-power hypothesis. Cognitive Psychology, 44(4), 339-387. https://doi.org/10.1006/cogp.2001.0769

Hambrick, D. Z., Pink, J. E., Meinz, E. J., Pettibone, J. C., \& Oswald, F. L. (2008). The roles of ability, personality, and interests in acquiring current events knowledge: A longitudinal study. Intelligence, 36(3), 261-278. https://doi.org/10.1016/j.intell.2007.06.004

Hartung, J., Doebler, P., Schroeders, U., \& Wilhelm, O. (2018). Dedifferentiation and differentiation of intelligence in adults across age and years of education. Intelligence, 69, 37-49. https://doi.org/10.1016/j.intell.2018.04.003 
Hartung, J., Engelhardt, L. E., Thibodeaux, M. L., Harden, K. P., \& Tucker-Drob, E. M. (2020). Developmental transformations in the structure of executive functions. Journal of Experimental Child Psychology, 189, 104681. https://doi.org/10.1016/j.jecp.2019.104681

Hartung, J., Spormann, S. S., Moshagen, M., \& Wilhelm, O. (2021). Structural differences in life satisfaction in a U.S. adult sample across age. Journal of Personality, jopy.12654. https://doi.org/10.1111/jopy.12654

Hertzog, C. K. (2009). Use it or lose it: An old hypothesis, new evidence, and an ongoing controversy. In H. B. Bosworth \& C. K. Hertzog (Eds.), Aging and cognition: Research methodologies and empirical advances (pp. 161-180). American Psychological Association. https://doi.org/10.1037/11882-008

Hildebrandt, A., Lüdtke, O., Robitzsch, A., Sommer, C., \& Wilhelm, O. (2016). Exploring factor model parameters across continuous variables with local structural equation models. Multivariate Behavioral Research, 51(2-3), 257-258. https://doi.org/10.1080/00273171.2016.1142856

Hildebrandt, A., Sommer, W., Herzmann, G., \& Wilhelm, O. (2010). Structural invariance and age-related performance differences in face cognition. Psychology and Aging, 25(4), 794-810. https://doi.org/10.1037/a0019774

Hildebrandt, A., Wilhelm, O., \& Robitzsch, A. (2009). Complementary and competing factor analytic approaches for the investigation of measurement invariance. Review of Psychology, 16(2), 17.

Holland, J. L. (1997). Making vocational choices: A theory of vocational personalities and work environments (3rd ed.). Psychological Assessment Resources. 
Horn, J. L., \& McArdle, J. J. (1992). A practical and theoretical guide to measurement invariance in aging research. Experimental Aging Research, 18(3), 117-144. https://doi.org/10.1080/03610739208253916

Hu, L., \& Bentler, P. M. (1999). Cutoff criteria for fit indexes in covariance structure analysis: Conventional criteria versus new alternatives. Structural Equation Modeling: A Multidisciplinary Journal, 6(1), 1-55. https://doi.org/10.1080/10705519909540118

Li, S.-C., Lindenberger, U., Hommel, B., Aschersleben, G., Prinz, W., \& Baltes, P. B. (2004). Transformations in the couplings among intellectual abilities and constituent cognitive processes across the life span. Psychological Science, 15(3), 155-163. https://doi.org/10.1111/j.0956-7976.2004.01503003.x

Lindenberger, U., Singer, T., \& Baltes, P. B. (2002). Longitudinal selectivity in aging populations: Separating mortality-associated versus experimental components in the Berlin Aging Study (BASE). The Journals of Gerontology Series B: Psychological Sciences and Social Sciences, 57(6), P474-P482. https://doi.org/10.1093/geronb/57.6.P474

Little, T. D., Cunningham, W. A., Shahar, G., \& Widaman, K. F. (2002). To parcel or not to parcel: Exploring the question, weighing the merits. Structural Equation Modeling, 9(2), 151-173. https://doi.org/10.1207/S15328007SEM0902_1

MacCallum, R. C., Zhang, S., Preacher, K. J., \& Rucker, D. D. (2002). On the practice of dichotomization of quantitative variables. Psychological Methods, 7(1), 19-40. https://doi.org/10.1037/1082-989X.7.1.19

Matthews, F. E., Arthur, A., Barnes, L. E., Bond, J., Jagger, C., Robinson, L., \& Brayne, C. (2013). A two-decade comparison of prevalence of dementia in individuals aged 65 years 
and older from three geographical areas of England: Results of the Cognitive Function and Ageing Study I and II. The Lancet, 382, 1405-1412. https://doi.org/10.1016/S01406736(13)61570-6

McArdle, J. J., Ferrer-Caja, E., Hamagami, F., \& Woodcock, R. W. (2002). Comparative longitudinal structural analyses of the growth and decline of multiple intellectual abilities over the life span. Developmental Psychology, 38(1), 115-142. https://doi.org/10.1037/0012-1649.38.1.115

McCrae, R. R., \& Costa, P. T. (1997). Conceptions and correlates of openness to experience. In R. Hogan, J. Johnson, \& S. Briggs (Eds.), Handbook of Personality Psychology (pp. 825847). Academic Press.

McDonald, R. P. (1999). Test theory: A unified treatment. Erlbaum.

McKay, D. A., \& Tokar, D. M. (2012). The HEXACO and five-factor models of personality in relation to RIASEC vocational interests. Journal of Vocational Behavior, 81(2), 138-149. https://doi.org/10.1016/j.jvb.2012.05.006

Meade, A. W., \& Lautenschlager, G. J. (2004). A monte-carlo study of confirmatory factor analytic tests of measurement equivalence/invariance. Structural Equation Modeling: A Multidisciplinary Journal, 11(1), 60-72. https://doi.org/10.1207/S15328007SEM1101_5

Molenaar, D. (2020). A flexible moderated factor analysis approach to test for measurement invariance across a continuous variable. Psychological Methods. https://doi.org/10.1037/met0000360

Molenaar, D., Dolan, C. V., Wicherts, J. M., \& van der Maas, H. L. J. (2010). Modeling differentiation of cognitive abilities within the higher-order factor model using moderated factor analysis. Intelligence, 38(6), 611-624. https://doi.org/10.1016/j.intell.2010.09.002 
Mussel, P. (2013). Intellect: A theoretical framework for personality traits related to intellectual achievements. Journal of Personality and Social Psychology, 104(5), 885-906. https://doi.org/10.1037/a0031918

Olaru, G., \& Allemand, M. (in press). Correlated personality change across time and age. European Journal of Personality.

Olaru, G., Robitzsch, A., Hildebrandt, A., \& Schroeders, U. (2020). Local Structural Equation Modeling for Longitudinal Data. PsyArXiv. https://doi.org/10.31234/osf.io/q79c5

Olaru, G., Schroeders, U., Hartung, J., \& Wilhelm, O. (2019). Ant colony optimization and local weighted structural equation modeling. A tutorial on novel item and person sampling procedures for personality research. European Journal of Personality, 33(3), 400-419. https://doi.org/10.1002/per.2195

Olaru, G., Witthöft, M., \& Wilhelm, O. (2015). Methods matter: Testing competing models for designing short-scale Big-Five assessments. Journal of Research in Personality, 59, 5668. https://doi.org/10.1016/j.jrp.2015.09.001

Pfost, M., Hattie, J., Dörfler, T., \& Artelt, C. (2014). Individual differences in reading development: A review of 25 years of empirical research on matthew effects in reading. Review of Educational Research, 84(2), 203-244. https://doi.org/10.3102/0034654313509492

Pornprasertmanit, S., Miller, P., Schoemann, A., \& Jorgensen, T. D. (2020). Simsem: SIMulated Structural Equation Modeling. R package version 0.5-15. https://CRAN.Rproject.org/package $=$ simsem

R Core Team. (2020). R: A Language and Environment for Statistical Computing. R Foundation for Statistical Computing. https://www.R-project.org/ 
Robitzsch, A. (2020). sirt: Supplementary item response theory models (Version $R$ package version 3.9-4). https://cran.r-project.org/web/packages/sirt/sirt.pdf

Rolfhus, E. L., \& Ackerman, P. L. (1999). Assessing individual differences in knowledge: Knowledge, intelligence, and related traits. Journal of Educational Psychology, 91(3), 511-526. https://doi.org/10.1037/0022-0663.91.3.511

Rönnlund, M., Nyberg, L., Bäckman, L., \& Nilsson, L.-G. (2005). Stability, growth, and decline in adult life span development of declarative memory: Cross-sectional and longitudinal data from a population-based study. Psychology and Aging, 20(1), 3-18. https://doi.org/10.1037/0882-7974.20.1.3

Rosseel, Y. (2012). lavaan: An R package for structural equation modeling. Journal of Statistical Software, 48(2). https://doi.org/10.18637/jss.v048.i02

Savi, A. O., Marsman, M., van Der Maas, H. L. J., \& Maris, G. K. J. (2019). The wiring of intelligence. Perspectives on Psychological Science, 14(6), 1034-1061. https://doi.org/10.1177/1745691619866447

Schipolowski, S., Wilhelm, O., \& Schroeders, U. (2014). On the nature of crystallized intelligence: The relationship between verbal ability and factual knowledge. Intelligence, 46, 156-168. https://doi.org/10.1016/j.intell.2014.05.014

Schmiedek, F., Lövdén, M., von Oertzen, T., \& Lindenberger, U. (2019). Within-person structures of daily cognitive performance cannot be inferred from between-person structures of cognitive abilities. PeerJ Preprints, 7:e27576v1. https://doi.org/10.7287/peerj.preprints.27576v1 
Schneider, W. J., \& McGrew, K. S. (2012). The Cattell-Horn-Carroll model of intelligence. In D. P. Flanagan \& P. L. Harrison (Eds.), Contemporary intellectual assessment: Theories, tests and issues (3rd ed., pp. 99-144). Guilford Press.

Schroeders, U., Schipolowski, S., \& Wilhelm, O. (2015). Age-related changes in the mean and covariance structure of fluid and crystallized intelligence in childhood and adolescence. Intelligence, 48, 15-29. https://doi.org/10.1016/j.intell.2014.10.006

Schroeders, U., Schipolowski, S., Zettler, I., Golle, J., \& Wilhelm, O. (2016). Do the smart get smarter? Development of fluid and crystallized intelligence in 3rd grade. Intelligence, 59, 84-95. https://doi.org/10.1016/j.intell.2016.08.003

Schroeders, U., Watrin, L., \& Wilhelm, O. (2021). Age-related nuances in knowledge assessment. Intelligence, 85, 101526. https://doi.org/10.1016/j.intell.2021.101526

Schroeders, U., Wilhelm, O., \& Olaru, G. (2016). The influence of item sampling on sex differences in knowledge tests. Intelligence, 58, 22-32. https://doi.org/10.1016/j.intell.2016.06.003

Simonsmeier, B. A., Flaig, M., Deiglmayr, A., Schalk, L., \& Schneider, M. (2021). Domainspecific prior knowledge and learning: A meta-analysis. Educational Psychologist. https://doi.org/10.1080/00461520.2021.1939700

Skibbe, L. E., Grimm, K. J., Stanton-Chapman, T. L., Justice, L. M., Pence, K. L., \& Bowles, R. P. (2008). Reading trajectories of children with language difficulties from preschool through fifth grade. Language, Speech, and Hearing Services in Schools, 39(4), 475-486. https://doi.org/10.1044/0161-1461(2008/07-0016)

Sprague, B. N., Hyun, J., \& Molenaar, P. C. M. (2018). Revisiting measurement invariance in intelligence testing in aging research: Evidence for almost complete metric invariance 
across age groups. Journal for Person-Oriented Research, 3(2), 86-100.

https://doi.org/10.17505/jpor.2017.08

Steger, D., Schroeders, U., \& Wilhelm, O. (2019). On the dimensionality of crystallized intelligence: A smartphone-based assessment. Intelligence, 72, 76-85. https://doi.org/10.1016/j.intell.2018.12.002

Tucker-Drob, E. M. (2009). Differentiation of cognitive abilities across the life span. Developmental Psychology, 45(4), 1097-1118. https://doi.org/10.1037/a0015864

Tucker-Drob, E. M., \& Salthouse, T. A. (2008). Adult age trends in the relations among cognitive abilities. Psychology and Aging, 23(2), 453-460. https://doi.org/10.1037/08827974.23.2.453

Usami, S., Murayama, K., \& Hamaker, E. L. (2019). A unified framework of longitudinal models to examine reciprocal relations. Psychological Methods, 24(5), 637-657. https://doi.org/10.1037/met0000210

Voelkle, M. C., Brose, A., Schmiedek, F., \& Lindenberger, U. (2014). Toward a unified framework for the study of between-person and within-person structures: Building a bridge between two research paradigms. Multivariate Behavioral Research, 49(3), 193213. https://doi.org/10.1080/00273171.2014.889593

von Stumm, S., \& Ackerman, P. L. (2013). Investment and intellect: A review and meta-analysis. Psychological Bulletin, 139(4), 841-869. https://doi.org/10.1037/a0030746

Walberg, H. J., \& Tsai, S.-L. (1983). Matthew effects in education. American Educational Research Journal, 20(3), 359-373. https://doi.org/10.3102/00028312020003359 
Wicherts, J. M., \& Dolan, C. V. (2010). Measurement invariance in confirmatory factor analysis: An illustration using IQ test performance of minorities. Educational Measurement: Issues and Practice, 29(3), 39-47. https://doi.org/10.1111/j.1745-3992.2010.00182.x

Witherby, A. E., \& Carpenter, S. K. (2021). The rich-get-richer effect: Prior knowledge predicts new learning of domain-relevant information. Journal of Experimental Psychology: Learning, Memory, and Cognition. https://doi.org/10.1037/xlm0000996

Wohlwill, J. F. (1970). The age variable in psychological research. Psychological Review, 77(1), 49-64. https://doi.org/10.1037/h0028600

Yu, C.-Y. (2002). Evaluating cutoff criteria of model fit indices for latent variable models with binary and continuous outcomes [Doctoral dissertation, University of California]. https://www.statmodel.com/download/Yudissertation.pdf

Zelinski, E. M., \& Lewis, K. L. (2003). Adult age differences in multiple cognitive functions: Differentiation, dedifferentiation, or process-specific change? Psychology and Aging, 18(4), 727-745. https://doi.org/10.1037/0882-7974.18.4.727

Ziegler, M., Schroeter, T. A., Lüdtke, O., \& Roemer, L. (2018). The enriching interplay between openness and interest: A theoretical elaboration of the OFCI model and a first empirical test. Journal of Intelligence, 6(35), 1-22. https://doi.org/10.3390/jintelligence6030035 


\section{Appendix A}

Table 5

Zero-Order Correlations for Study Variables

\begin{tabular}{|c|c|c|c|c|c|c|c|c|c|c|c|c|c|c|c|c|c|}
\hline Variable & 1 & 2 & 3 & 4 & 5 & 6 & 7 & 8 & 9 & 10 & 11 & 12 & 13 & 14 & 15 & 16 & 17 \\
\hline 1. Law & $(.66)$ & & & & & & & & & & & & & & & & \\
\hline 2. Politics & .44 & (.66) & & & & & & & & & & & & & & & \\
\hline 3. Economics & .57 & .47 & $(.77)$ & & & & & & & & & & & & & & \\
\hline 4. Chemistry & .36 & .40 & .45 & $(.79)$ & & & & & & & & & & & & & \\
\hline 5. Mathematics & .35 & .40 & .42 & .60 & $(.78)$ & & & & & & & & & & & & \\
\hline 6. Physics & .33 & .38 & .43 & .58 & .53 & $(.70)$ & & & & & & & & & & & \\
\hline 7. Nutrition & .33 & .30 & .37 & .39 & .34 & .31 & $(.72)$ & & & & & & & & & & \\
\hline 8. Health & .31 & .27 & .33 & .35 & .30 & .27 & .48 & $(.60)$ & & & & & & & & & \\
\hline 9. Medicine & .33 & .29 & .35 & .40 & .31 & .30 & .51 & .47 & $(.74)$ & & & & & & & & \\
\hline 10. Arts & .43 & .46 & .47 & .41 & .37 & .35 & .48 & .36 & .45 & $(.81)$ & & & & & & & \\
\hline 11. Literature & .39 & .48 & .47 & .33 & .32 & .29 & .39 & .32 & .38 & .63 & $(.79)$ & & & & & & \\
\hline 12. Music & .39 & .44 & .41 & .37 & .31 & .30 & .45 & .32 & .40 & .63 & .61 & $(.77)$ & & & & & \\
\hline 13. Know. Total & .64 & .66 & .71 & .71 & .66 & .63 & .66 & .58 & .64 & .76 & .70 & .70 & $(.89)$ & & & & \\
\hline 14. O-Intellectual & .26 & .19 & .31 & .30 & .26 & .23 & .19 & .22 & .23 & .30 & .22 & .19 & .36 & (.74) & & & \\
\hline 15. O-Reflective & .02 & .00 & .04 & .04 & .08 & -.01 & .05 & .11 & .11 & .13 & .08 & .04 & .09 & .40 & $(.66)$ & & \\
\hline 16. O-Scientific & .09 & .16 & .16 & .21 & .13 & .21 & .10 & .13 & .15 & .18 & .11 & .15 & .22 & .38 & .37 & (75) & \\
\hline 17. Openness & .16 & .16 & .22 & .24 & .20 & .19 & .15 & .20 & .21 & .26 & .18 & .17 & .29 & .77 & .77 & .77 & $(.76)$ \\
\hline 18. Age & .09 & .15 & .02 & -.12 & -.20 & -.06 & .12 & .02 & .05 & .22 & .27 & .35 & .11 & -.10 & -.15 & .08 & -.08 \\
\hline
\end{tabular}

Note. $\mathrm{n}=1,629$. All correlations $|r|>=.06$ are significant $(p<.05)$. McDonald's $\omega$ reliability estimates are indicated in brackets on the diagonal. 